\title{
Front Matter: Volume 7786
}

, "Front Matter: Volume 7786," Proc. SPIE 7786, Current Developments in Lens Design and Optical Engineering XI; and Advances in Thin Film Coatings VI, 778601 (27 September 2010); doi: 10.1117/12.878975

SPIE Event: SPIE Optical Engineering + Applications, 2010, San Diego, California, United States 


\section{PROCEEDINGS OF SPIE}

\section{Current Developments in Lens Design and Optical Engineering $\mathrm{XI}$; and Advances in Thin Film Coatings VI}

R. Barry Johnson

Virendra N. Mahajan

Simon Thibault

Editors

1-3 August 2010

San Diego, California, United States

Sponsored and Published by

SPIE 
The papers included in this volume were part of the technical conference cited on the cover and title page. Papers were selected and subject to review by the editors and conference program committee. Some conference presentations may not be available for publication. The papers published in these proceedings reflect the work and thoughts of the authors and are published herein as submitted. The publisher is not responsible for the validity of the information or for any outcomes resulting from reliance thereon.

Please use the following format to cite material from this book:

Author(s), "Title of Paper," in Current Developments in Lens Design and Optical Engineering XI; and Advances in Thin Film Coatings VI, edited by R. Barry Johnson, Virendra N. Mahajan, Simon Thibault, Proceedings of SPIE Vol. 7786 (SPIE, Bellingham, WA, 2010) Article CID Number.

ISSN 0277-786X

ISBN 9780819482822

Published by

SPIE

P.O. Box 10, Bellingham, Washington 98227-0010 USA

Telephone +1 3606763290 (Pacific Time) · Fax +1 3606471445

SPIE.org

Copyright (C) 2010, Society of Photo-Optical Instrumentation Engineers

Copying of material in this book for internal or personal use, or for the internal or personal use of specific clients, beyond the fair use provisions granted by the U.S. Copyright Law is authorized by SPIE subject to payment of copying fees. The Transactional Reporting Service base fee for this volume is $\$ 18.00$ per article (or portion thereof), which should be paid directly to the Copyright Clearance Center (CCC), 222 Rosewood Drive, Danvers, MA 01923. Payment may also be made electronically through CCC Online at copyright.com. Other copying for republication, resale, advertising or promotion, or any form of systematic or multiple reproduction of any material in this book is prohibited except with permission in writing from the publisher. The CCC fee code is 0277-786X/10/\$18.00.

Printed in the United States of America.

Publication of record for individual papers is online in the SPIE Digital Library.

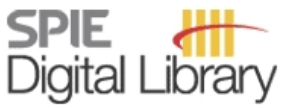

SPIEDigitalLibrary.org

Paper Numbering: Proceedings of SPIE follow an e-First publication model, with papers published first online and then in print and on CD-ROM. Papers are published as they are submitted and meet publication criteria. A unique, consistent, permanent citation identifier (CID) number is assigned to each article at the time of the first publication. Utilization of CIDs allows articles to be fully citable as soon they are published online, and connects the same identifier to all online, print, and electronic versions of the publication. SPIE uses a six-digit CID article numbering system in which:

- The first four digits correspond to the SPIE volume number.

- The last two digits indicate publication order within the volume using a Base 36 numbering system employing both numerals and letters. These two-number sets start with 00, 01, 02, 03, 04, $05,06,07,08,09,0 A, 0 B \ldots 0 Z$, followed by 10-1Z, 20-2Z, etc.

The CID number appears on each page of the manuscript. The complete citation is used on the first page, and an abbreviated version on subsequent pages. Numbers in the index correspond to the last two digits of the six-digit CID number. 


\section{Contents}

vii Conference Committee

ix Introduction

Manuscripts from Joint Session with Conference 7812: Imaging Spectrometry XV

xiii The Schmidt-Dyson: a fast space-borne wide-field hyperspectral imager [7812-19]

R. Lucke, Naval Research Lab. (United States); J. Fisher, Brandywine Photonics LLC (United States)

xxvi MAKO: a high-performance, airborne imaging spectrometer for the long-wave infrared [7812-20]

D. W. Warren, R. H. Boucher, D. J. Gutierrez, E. R. Keim, M. G. Sivjee, The Aerospace Corp. (United States)

xxxvi Optical design, performance, and tolerancing of next-generation airborne imaging spectrometers [7812-22]

H. A. Bender, P. Mouroulis, R. O. Green, D. W. Wilson, Jet Propulsion Lab. (United States)

xlviii Polarization and stray light considerations for the portable remote imaging spectrometer (PRISM [7812-24]

B. Van Gorp, P. Mouroulis, D. Wilson, K. Balasubramanian, Jet Propulsion Lab. (United States)

lix Holographic electro-optic thin film stacks for airborne hyperspectral imaging [7812-25]

S. K. Shriyan, A. K. Fontecchio, Drexel Univ. (Unites States)

SSL RESEARCH AT NATIONAL CENTRAL UNIVERSITY IN TAIWAN

778602 CCT-dependent calibration for colorimeters (Invited Paper) [7786-01]

T.-H. Yang, S.-F. Liao, C.-C. Lee, National Central Univ. (Taiwan)

778603 High performance of color mixing and projection lighting based on color LEDs [7786-02]

W.-T. Chien, S.-I. Ho, C.-Y. Tsai, C.-C. Sun, National Central Univ. (Taiwan)

778604 Research on angle-selective filters of phosphor color wheel for LED projectors [7786-03] T.-C. Wei, C.-C. Kuo, National Central Univ. (Taiwan); J.-J. Huang, Delta Electronics, Inc. (Taiwan); C.-C. Lee, National Central Univ. (Taiwan)

778605 High-efficiency LED street light using micro-lens array [7786-04]

X.-H. Lee, C.-C. Sun, National Central Univ. (Taiwan)

778606 Optical performance as a function of phosphor particle number in white LED [7786-05]

C.-C. Chen, C.-Y. Chen, W.-T. Chien, T.-H. Yang, C.-C. Sun, National Central Univ. (Taiwan) 
778607 A novel approach for structural synthesis of zoom systems [7786-06]

L. N. Hazra, S. Pal, Univ. of Calcutta (India)

778609 Accelerating diffractive optics design with GPU-based parallel technique [7786-08] K. Liu, H. Li, X. Zhang, Huazhong Univ. of Science and Technology (China) and Wuhan National Lab. for Optoelectronics (China); D. Li, M. Wei, B. Li, Huazhong Univ. of Science and Technology (China); C. Xie, Wuhan National Lab. for Optoelectronics (China); T. Zhang, Huazhong Univ. of Science and Technology (China)

7786 OA Ultra-compact close-up microoptical imaging system [7786-10] A. Brückner, J. Duparré, F. Wippermann, R. Leitel, P. Dannberg, A. Bräuer, Fraunhofer-Institut für Angewandte Optik und Feinmechanik (Germany)

7786 OB Design and implementation of recording and readout system for micro-holographic optical data storage [7786-12]

Y. Takashima, L. Hesselink, Stanford Univ. (United States)

\section{ASTRONOMICAL OPTICS}

7786 OD Perceptual image quality and telescope performance ranking [7786-34]

J. K. Lentz, J. E. Harvey, CREOL, The College of Optics and Photonics, Univ. of Central Florida (United States); K. H. Marshall, J. Salg, Damewood Optical Maintenance Lab. (United

States); J. B. Houston, Houston Research Associates (United States)

\section{DEVELOPMENTS IN MATERIALS AND TECHNIQUES}

7786 OF lon-beam figuring (IBF) for high-precision optics becomes affordable [7786-16] S. Kiontke, M. Demmler, asphericon GmbH (Germany); M. Zeuner, F. Allenstein, T. Dunger, M. Nestler, Roth \& Rau MicroSystems GmbH (Germany)

7786 OG Photonic jets and Bessel beams [7786-17]

A. Devilez, B. Stout, N. Bonod, Institut Fresnel, Aix-Marseille Univ., CNRS (France)

$7786 \mathrm{OH} \quad$ Flat liquid crystal diffractive lenses with variable focus and magnification [7786-18] P. Valley, M. R. Dodge, J. Schwiegerling, D. Mathine, G. Peyman, N. Peyghambarian, College of Optical Sciences, The Univ. of Arizona (United States)

7786 Ol Color patterns in a tapered lightpipe with RGB LEDs [7786-19]

D. Esparza, I. Moreno, Univ. Autónoma de Zacatecas (Mexico)

\section{THIN FILM OPTICAL COATINGS I}

7786 0J Accelerated atmospheric corrosion testing of electroplated gold mirror coatings [7786-20] C.-T. Chu, D. R. Alaan, D. P. Taylor, The Aerospace Corp. (United States) 
7786 OK Development and verification of high durability infrared transparent coating for airborne usage [7786-21]

A. L. Avşar, H. A. Salman, A. E. S. Özhan, A. Çolakoğlu, ASELSAN Inc. (Turkey)

7786 OM Spectroscopic ellipsometry of a-Si/SiO 2 large waveband coating for the JWST-FGS-TFI etalon plates fabrication [7786-23]

M. Poirier, INO Quebec (Canada); C. Evans, C. Haley, D. Touahri, COM DEV Ltd. (Canada);

R. Doyon, Univ. de Montréal (Canada)

7786 ON Antireflection coating on metallic substrates for solar energy and display applications [7786-24]

W.-Y. Hsiao, National Central Univ. (Taiwan); C.-J. Tang, Minghsin Univ. of Science and Technology (Taiwan); K.-H. Lee, National Central Univ. (Taiwan); C.-C. Jaing, Minghsin Univ. of Science and Technology (Taiwan); C.-C. Kuo, National Central Univ. (Taiwan); H.-C. Chen, National Yunlin Univ. of Science and Technology (Taiwan); H.-H. Chang, Vanung Univ. (Taiwan); C.-C. Lee, National Central Univ. (Taiwan)

778600 Characterization of feathering of optical coating [7786-25]

C. Buchholz, D. Krevor, Rockwell Collins, Inc. (United States)

THIN FILM OPTICAL COATINGS II

$7786 \mathrm{OQ}$ Improving the optical and electrical properties of fluorine-doped tin oxide films by various post-annealing treatments [7786-27]

P.-J. Chen, B.-H. Liao, C.-C. Kuo, C.-C. Lee, National Central Univ. (Taiwan)

7786 OR $\quad \mathrm{Nb}$-doped $\mathrm{TiO}_{2}$ transparent conducting coating by pulsed DC magnetron co-sputtering [7786-28]

S. -H. Peng, C.-C. Kuo, M.-C. Li, S.-H. Tsai, C.-C. Lee, National Central Univ. (Taiwan)

7786 OS Electro-chromic device with GZO as a conductive layer [7786-29]

C.-C. Chan, National Central Univ. (Taiwan); C.-J. Tang, Minghsin Univ. of Science and Technology (Taiwan); K.-H. Lee, National Central Univ. (Taiwan); C.-C. Jaing, Minghsin Univ. of Science and Technology (Taiwan); C.-C. Kuo, National Central Univ. (Taiwan);

H.-C. Chen, National Yunlin Univ. of Science and Technology (Taiwan); C.-C. Lee, National Central Univ. (Taiwan)

\section{SYSTEM AND COMPONENT TEST}

7786 OU Dynamic modeling of optical systems in order to study vibration effect on performance [7786-31]

A. L. Avşar, ASELSAN Inc. (Turkey); H. N. Özgüven, Middle East Technical Univ. (Turkey)

$7786 \mathrm{OV}$ Study of the influence of the tetrahedral reflectors properties on autocollimating systems characteristics [7786-32]

A. G. Anisimov, E. A. Tsyganok, I. A. Konyakhin, Saint-Petersburg State Univ. of Information Technologies, Mechanics and Optics (Russian Federation)

7786 OW Dedicated testing setup for panoramic lenses [7786-33]

A.-S. Poulin-Girard, J. Parent, S. Thibault, P. Désaulniers, Univ. Laval (Canada) 
7786 0X Diffraction depth of focus in optical microscope [7786-11]

V. Borovytsky, A. Fesenko, National Technical Univ. of Ukraine (Ukraine)

7786 OY Optical design of the JWST fine guider sensor [7786-35]

S. H. Zheng, C. Evans, COM DEV International Ltd. (Canada)

778611 Design and fabrication of super mirrors on the Zerodur substrate [7786-38]

H.-J. Cho, Y.-Z. Jeon, Daeduk Univ. (Korea, Republic of)

778612 The design and fabrication of telecentric lens with large field of view [7786-39]

C.-C.Chang, K.-C. Huang, W.-H. Wu, Instrument Technology Research Ctr. (Taiwan);

Y.-H. Lin, National Pingtung Univ. of Science Technology (Taiwan)

778613 Bound-abrasive grinding and polishing of surfaces of optical materials [7786-40]

Y. D. Filatov, O. Yu. Filatov, V. Bakul Institute for Superhard Materials (Ukraine);

G. Monteil, Ecole Nationale Supérieure Mécanique et des Microtechniques de Besançon

(France); U. Heisel, M. Storchak, Univ. Stuttgart (Germany)

778614 AR coatings on laser crystals for HiPER project [7786-41]

J. Oulehla, Institute of Scientific Instruments of the ASCR, v.v.i. (Czech Republic) and Palacky

Univ. (Czech Republic); P. Pokorný, Institute of Scientific Instruments of the ASCR, v.v.i.

(Czech Republic)

778616 Analysis of opto-mechanical performance of a tunable liquid lens [7786-43]

A. Santiago-Alvarado, Univ. Tecnológica de la Mixteca (Mexico); S. Vázquez-Montiel, Instituto Nacional de Astrofísica, Óptica y Electronica (Mexico); J. González-García, Univ. Tecnológica de la Mixteca (Mexico); J. Muñoz-López, Instituto Nacional de Astrofísica, Óptica y Electronica (Mexico); M. Campos García, Univ. Nacional Autónoma de México (Mexico)

778617 LED phototherapy system in skin treatment and detecting [7786-44]

H.-C. Chen, National Yunlin Univ. of Science and Technology (Taiwan); J.-H. Wu, Ming Chuan Univ. (Taiwan); C.-H. Lin, National Yunlin Univ. of Science and Technology (Taiwan);

S.-H. Ma, Feng Chia Univ. (Taiwan)

778618 Barium fluoride and glass combinations for short-wave infrared designs [7786-45]

D. W. Warren, The Aerospace Corp. (United States)

778619 Investigation of the temperature dependent complex index of refraction of infrared thin-film coating materials [7786-46]

L. C. Alves, Deposition Sciences, Inc. (United States)

Author Index 


\section{Conference Committee}

Program Track Chair

R. John Koshel, Photon Engineering LLC (United States) and College of Optical Sciences, The University of Arizona (United States)

\section{Conference Chairs}

R. Barry Johnson, Alabama A\&M University (United States) and Consultant (United States)

Virendra N. Mahajan, The Aerospace Corporation (United States)

Simon Thibault, ImmerVision (Canada) and Université Laval (Canada)

\section{Program Committee}

Julie Bentley, University of Rochester (United States)

Florian Bociort, Technische Universiteit Delft (Netherlands)

Michael Chrisp, Lawrence Livermore National Laboratory (United States)

Apostolos Deslis, InPhase Technologies Inc. (United States)

Robert E. Fischer, OPTICS 1, Inc. (United States)

Alexander V. Goncharov, National University of Ireland, Galway (Ireland)

James E. Harvey, CREOL, The College of Optics and Photonics, University of Central Florida (United States)

Lakshminarayan Hazra, The Optical Society of India (India) and University of Calcutta (India)

Daniel Malacara-Doblado, Centro de Investigaciones en Óptica, A.C. (Mexico)

Michael Mandina, Optimax Systems, Inc. (United States)

Laurent Mazuray, EADS Astrium (France)

Pantazis Z. Mouroulis, Jet Propulsion Laboratory (United States)

Ching-Cherng Sun, National Central University (Taiwan)

Akiyoshi Suzuki, Canon Inc. (Japan)

Yuzuru Takashima, Stanford University (United States)

Jennifer A. Turner-Valle, College of Optical Sciences, The University of Arizona (United States)

Sergio Vázquez-Montiel, Instituto Nacional de Astrofísica, Óptica y Electrónica (Mexico)

Yongtian Wang, Beijing Institute of Technology (China)

Andrew P. Wood, Qioptiq Ltd. (United Kingdom)

Maria Josefa Yzuel, University Autònoma de Barcelona (Spain)

James M. Zavislan, University of Rochester (United States) 
Session Chairs

1 SSL Research at National Central University in Taiwan

Ching-Cherng Sun, National Central University (Taiwan)

2 Lens Design and Optical Engineering

R. Barry Johnson, Alabama A\&M University (United States) and Consultant (United States)

3 Astronomical Optics

Virendra N. Mahajan, The Aerospace Corp. (United States)

4 Developments in Materials and Techniques

Michael Mandina, Optimax Systems, Inc. (United States)

5 Thin Film Optical Coatings I

Jennifer A. Turner-Valle, College of Optical Sciences, The University of Arizona (United States)

6 Optical Design and Engineering of Hyperspectral Sensors: Joint Session with Conference 7812:

Pantazis Z. Mouroulis, Jet Propulsion Laboratory (United States)

7 Thin Film Optical Coatings II

Jennifer A. Turner-Valle, College of Optical Sciences, The University of Arizona (United States)

Andrew P. Wood, Qioptiq Ltd. (United Kingdom)

8 System and Component Test

Lakshminarayan Hazra, University of Calcutta (India) 


\section{Introduction}

This year, our conference on Current Developments in Lens Design and Optical Engineering also included Advances in Thin Film Coatings. The papers were presented in eight sessions, one of which was held jointly with the Imaging Spectroscopy Conference 7812. There was a strong session of poster papers as well. Some papers were withdrawn or cancelled due to visa problems of the overseas contributors. A total of 40 manuscripts appear in the Proceedings that include 30 oral and 10 poster papers, including the five oral papers from the joint session. A brief summary of each session is given below with the name and affiliation of the session chair given in parentheses.

Session 1: SSL Research at National Central University in Taiwan (C. C. Sun, National Central University)

National Central University is at the forefront of LED research. LEDs are regarded as one of the most important and promising light source in the $21^{\text {st }}$ century. The advantages in energy saving, design freedom in color, and optics and human factor, all attract intense attention by researchers in various fields. Optical design is important for lighting concerns not only in lens or mirror optimization, but also in phosphor scattering and object diffusion, and not only in getting desired illumination uniformity, but also in how to extract light from a trapping cavity. SSL (solid state light) will continue to be a hot topic in optical design.

In this session, one invited and four contributed papers were presented. T. H. Yang in his invited paper reported the novel progress on colorimeter calibration, which enables accurate measurements of the chromatic property of LEDs under various practical correlate color temperatures (CCT). The second paper was presented by W. T. Chien, who reported a study of color mixing with a compact optical element. Through power adjustment and appropriate total internal reflection (TIR) lens design, the light emitted by red, green, and blue (RGB) LEDs can be color mixed to meet the CCT at $6500 \mathrm{~K}$, $4500 \mathrm{~K}$ and $3000 \mathrm{~K}$ and be projected at an angle of $40 \circ$ of FWHM. The third paper was presented by T. C Wei, who reported a design of color filter incorporated with phosphor to recycle light at large incident and scattering angles, and then increase not only the directionality of the integrating light source but also the system optical efficiency. In the fourth paper, X. H. Lee presented a design of a street light with TIR lens design incorporated with a specific diffuser. The advantage of the design is that the optical utilization factor exceeds $80 \%$, which is much higher than the $40 \%$ value of a normal design. In the last and fifth paper of this session, C. C. Chen reported the results of an in-depth study on the phosphor particle number, which is regarded as the most important factor to determine the CCT as well as luminous efficacy of an LED package. 


\section{Session 2: Lens Design and Optical Engineering (R. B. Johnson, Consultant and Alabama A\&M University)}

Due to visa problems, two of the six papers planned in the program were not presented. The first paper was presented by L. N. Hazra on a new approach for synthesis of thin lens structures for zoom lenses using evolutionary programming based upon genetic algorithms. Although the work is in its early stages, it does show interesting promise for future zoom lens system design. The second paper by K. Liu et al., and presented by the session chair R. B. Johnson, discussed GPU (graphics processing unit)-based data parallel techniques to reduce the computational time in the design of diffractive optics. The method was successfully demonstrated by computation of a diffractive element and followed by fabrication and evaluation of the element. In the next paper, A. Brückner, et al. discussed their work in developing ultra-compact close-up microoptical imaging systems for application in machine vision and biological imaging. Their method utilizes an innovative method of using a multi-aperture approach to shorten the total track length and a stack of several two-dimensional arrays of refractive microlenses. They have achieved demonstration of a compact system having high resolution without scanning. The final paper was presented by $\mathrm{Y}$. Takashima in which he discussed the design and implementation of a recording and readout system for micro-holographic optical data storage. A lens design was achieved for a multilayer micro holographic optical recording system having a NA $=0.4$ and a recording depth range of $0.4 \mathrm{~mm}$ using their proposed power arrangement, as explained in the paper.

\section{Session 3: Astronomical Optics (V. N. Mahajan, The Aerospace Corporation)}

This year, we received some papers in the area of astronomical optics. However, only one paper is included in the Proceedings due to visa problems of some of the presenters. J. Lents et al. discuss perceptual image quality and performance ranking of telescopes used for imaging space launch vehicles.

Session 4: Developments in Materials and Techniques (M. Mandina, Optimax Systems, Inc.)

A new lon milling system manufactured by Roth Rau was discussed by $\mathrm{S}$. Kiontke. The system figures lenses up to $200 \mathrm{~mm}$ diameter and was designed for production of precision optics, most notably spheres and aspheres. Results presented demonstrated a 10x improvement in the peak-to-valley figure. The process parameters are adjustable so beam size can be optimized for fast removal, and then altered for more optimal surface correction. Analyses of micron-scale dielectric microspheres as lens elements was presented by A. Devilez et al. The focusing characteristics and the resulting photonic jet are discussed. Applications for molecular imaging and directional antenna are also considered. Flat-liquid crystal-diffractive lenses with variable focus and magnification were presented by P. Valley. Annular liquid crystal shutters are integrated with a multi-focused diffractive lens element that enables multistepped focal length capability. These tunable-focus flat liquid crystal diffractive lenses (LCDL) employ binary Fresnel zone electrodes and are fabricated on Indium-Tin-Oxide using conventional micro-photolithography. 
Sample images taken through the lens at various magnifications were shown. A means of calculating color maps for rectangular tapered light pipes was presented by I. Mereno. The premise is that a tapered lightpipe behaves as a three-dimensional kaleidoscope. The method enables simulation of diode placement and light pipe dimension modification yielding both representative color pattern and color map.

Session 5: Thin Film Optical Coatings I (J. Turner-Valle, College of Optical Sciences, The University of Arizona)

The papers presented in this session illustrate the great depth and diversity of optical thin film applications in existence today. In this era of well-understood and repeatable deposition of optical coatings, it is rare to find an application, whether consumer- or aerospace-driven, where thin film coatings are not used to control the transmission, reflection, and absorption of light. Likewise, the authors in this conference covered a wide range of topics spanning the full range of applications.

C. T. Chu presented test results of accelerated atmospheric corrosion of electroplated gold-mirror coatings. They are relevant to infrared optics used in industrial, space, and military applications where gold-coated mirrors are exposed to atmosphere. The changes in optical properties of these mirrors were correlated with the morphology of corrosion features. A. Avsar presented results from the development of a rain erosion-resistant hard carbon coating for germanium substrates used as windows in airborne infrared optical systems. He showed improvement in the damage resistance of germanium substrates coated with a diamond like carbon coating and correlation of the observed damage to that predicted by modeling. M. Poirier presented spectroscopic ellipsometry of an amorphous silicon/silica coating for fabrication of the James Webb Space Telescope's Fine Guidance Sensor Tunable Filter Imager (JWST-FGS-TFI) etalon plates, which must perform well over a 1-5 $\mathrm{mm}$ wavelength range. He refines optical properties characterization for the deposited layers in the a-Si/SiO${ }_{2}$ stack based on a multiple-layer ellipsometric model. W. Y. Hsiao presented the design and deposition of anti-reflection coatings on an aluminum substrate for a solar and the deposition of anti-reflection and high-reflector coatings for an organic light-emitting diode (OLED) device. He gave results for the two cases and compared them with the theory. C. Buchholz presented the characterization of optical coating edge feathering for application in helmet mounted displays.

\section{Session 6: Optical Design and Engineering of Hyperspectral Sensors (P. Mouroulis, Jet Propulsion Laboratory)}

A session on the Optical Design and Engineering of Hyperspectral Sensors was held for the first time in conjunction with the long-standing Imaging Spectrometry conference. Five papers were presented, which will be indexed in the Imaging Spectrometry volume 7812, but are also reprinted here. Three of these presented designs based on the Dyson spectrometer form, for spectral ranges spanning the visible and thermal infrared, showing the flexibility of this design form. One paper presented a novel electro-optic 
stacked filter concept that can be tailored to produce several bands centered at specific wavelengths of interest, while another dealt with the engineering and tolerancing aspects of imaging spectrometers that are necessary in order to achieve the tight calibration and stability specifications required of high-accuracy spectroscopy.

Session 7: Thin Film Optical Coatings II (A. Wood, Qioptic Ltd. and J. TurnerValle, College of Optical Sciences, The University of Arizona)

In the first paper, P. Z. Chen et al. describe a post-annealing technique for improving the optical and electrical properties of fluorine doped tin oxide films. The experimental arrangement to assess the variation of properties with temperature and optimizing the annealing process is described. The next paper by S. H. Peng describes a technique for producing a $\mathrm{Nb}$ doped $\mathrm{TiO}_{2}$ transparent conducting coating using a pulsed DC magnetron co-sputtering technique. The advantages of this film over alternatives are presented and experimental results form the films produced are discussed. The final paper by C. C. Chan describes an experiment to produce an electro-chromic device with GZO (gallium-doped zinc oxide) as a conductive layer and discusses the results. This technique is a potential alternative to ITO (indium tin oxide); a summary of applications is presented.

\section{Session 8: System and Component Test (L. N. Hazra, University of Calcutta)}

The four papers presented in this session cover a broad range of problems encountered in performance evaluation and testing of optical systems and components. The paper by $\mathrm{L}$. Zhao et al deals with characterization of image stabilization systems for tackling vibrations in camera. A dynamic model for studying the effect of vibration on system performance is presented in the paper by A. Avsar et al. The paper by A. Anisimov and I. Konyakhin reports studies on the effects of tetrahedral reflector properties on the characteristics of autocollimating systems. A dedicated test set up for panoramic lenses is described in the paper by A-S. Poulin-Girard et al.

\section{R. Barry Johnson Virendra N. Mahajan Simon Thibault}

